\title{
Age at First Conception and its Determinants of Ever-Married Women in Bangladesh
}

\author{
Mohammad Manjur Alam * \\ Assistant Professor, Department of Computer Science and Engineering, International Islamic University \\ Chittagong, Chattagram-4318, Bangladesh.
}

\begin{abstract}
Age at first conception is an important part of the reproductive process that identifies the level of fecundability and indicative fertility during the early stages of marriage. This study explores the age at first conception and its determinants of ever-married women in Bangladesh by extracting the recent Bangladesh Demographic and Health Surveys (BDHS 2017) data. Descriptive statistics, ANOVA, chisquare tests, and binary logistic regression analysis were carried out to analyze data. Overall, the mean age at first conception of Bangladeshi women is $17.82 \pm 3.29$ years with significant variations by different socio-demographic, cultural, and behavioral factors. Bivariate analysis of chi-square tests shows that all the independent variables have a significant effect on age at first conception. The finding of the binary logistic regression analysis revealed that respondents' current age, age at first cohabitation, respondents' education, and partners' education are the most important determinants of age at first conception in Bangladesh. Moreover, secondary $(\mathrm{OR}=0.743,95 \% \mathrm{CI}=0.622-0.886, \mathrm{P}<0.01)$ and higher educated women $(\mathrm{OR}=0.838,95 \% \mathrm{CI}=0.710-0.989, \mathrm{P}<0.05)$ were respectively less likely to having first conception at age above 17.25 years, compared to no educated women. Thus, to increase the age at the first conception and reduce the level of fertility, it is necessary to increase the age at the first marriage of the respondents and the level of education for both partners.
\end{abstract}

Keywords: marriage, age at first conception, education, Bangladesh

\section{Introduction}

The age at which a woman becomes pregnant for the first time is called the age at first conception. The age at first conception is one of the most important fertility traits of women's reproductive behavior, especially with far-reaching consequences of their reproductive health and social position. The first conception is an important and exhilarating event in human life. Once women get married, the most exciting event of their conjugal life is the first conception. Both family members are eagerly waiting for such an event. This event is a chance event. Generally, the age of women in the first conception is highly associated with socioeconomic, cultural, demographic, and social factors. Thus, it is important to explore the age at first conception in a traditional Bangladeshi society as it plays an important role in determining a woman's reproductive life and fertility. A woman's reproductive span begins with effective marriage and the timing of the first conception. As such marriage marks the beginning of the period of probable conception and childbearing. Thus, it is also measured the major determinant of fertility. Patterns of marriage indicate that marriage is almost universal in Bangladesh, like other South Asian regions, young age at marriage and early motherhood has been stimulated in Bangladesh (Jones, 2007). According to BDHS-2017, $59 \%$ of women aged 20-24 are married before the age of 18 years and $28 \%$ of women start having childbearing during adolescence. By extracted BDHS, 2011 data, Alam et al. (2016) found that the average age at first motherhood of Bangladeshi women was only 17.92 years. Data extracted from multiple indicator cluster surveys (MICSs) of Bangladesh 2017-2018, and 2018 found that the average at first birth of Bangladeshi women was 16.86 years, and the mean age at the first union in Bangladeshi women is lower than Ghana and Iraq (Saleheen et al. 2021). Previous studies have explored that in South Asia, about $60 \%$ of women start their conjugal life at the age of 18 and one fourth is married get married by the age of 15 (Mehra \& Agrawal, 2004), and the highest recorded teenaged pregnancy rate is in Bangladesh (35\%) followed by India (21\%) 
and Nepal (21\%) (Papri et al. 2016). Darroch et al. (2016) estimated that, in developing regions, each year, an estimated 21 million girls aged 15-19 years become pregnant and about 12 million of them follow live birth. Almost 7,777,000 births happen in adolescents under 15 years of age (UNFPA, 2015). Further, numerous observational studies have exposed that early and late childbearing is a threat to maternal and child health (Liu \& Zhang, 2014; Jolly et al. 2000; Chen et al. 2007). It is assume that, delay of the first conception may lead to lower levels of fertility where contraception is not widely used. For women who become pregnant at an older age, the risks for complications during pregnancy and in particular delivery are increased also the prevalence of adverse effects have been detected in their child (Joseph et al. 2005; Luke \& Brown, 2007).

Although most of the previous studies have been conducted on fertility, mortality, marriage, and birth. The elaborate study of age at first conception is not yet carried out in Bangladesh. Therefore, the main objective of this research work is to determine the age at first conception along with its associated factors among evermarried women in Bangladesh. More precisely, information related to prognostic factors associated with age at first conception is lacking in the South Asian region, as well as in Bangladesh, although age at first conception is an important indicator of reproductive span and fertility. For conducting the aforesaid segments the data are extracted from the recent Bangladesh Demographic and Health Survey (BDHS), 2017. Since there is not enough information about childbearing outside marriage in Bangladesh, we consider only the marital age in the first conception. Moreover, pregnancy without effective marriage or hidden marriage is extremely sensitive in Bangladesh.

\section{Objective of the present study}

The prime objective of this research work is to study an important segment of the reproductive span, mainly the age at first conception. However, the specific objectives of this study are -

i. To determine the mean age at first conception by background characteristics among ever-married women in Bangladesh;

ii. To identify the factors influencing the age at first conception in Bangladesh;

iii. To find out the prognostic factors of age at first conception by using logistic regression analysis.

\section{Materials and methods}

\subsection{Data Sources and sample design}

Data were extracted from Bangladesh Demographic Health and Survey (BDHS), 2017-2018. It was implemented by the National Institute of Population Research and Training under the Ministry of Health and Family Welfare, Government of Bangladesh. Based on a two-stage stratified population-based cluster sampling design, a total of 20,127 ever-married women aged 15-49 years were fruitfully interviewed (NIPORT et al. 2019). In the initial stage, 675 enumeration areas (EAs) were selected with probability proportional to $250 \mathrm{EA}$ in urban areas and 425 from rural areas. Then, in the next stage, an average of 30 households per EA was selected for the whole country using the systematic sampling procedure (NIPORT et al. 2019). Data were collected from October 2017 to March 2018 by United States Agency for International Development (USAID)/Bangladesh found.

\subsection{Dependent Variable}

To determine the age at the first conception of Bangladeshi women, we consider all live births, stillbirths, and currently pregnant respondents in the data set of BDHS, 2017. Therefore, in this study, we have determined the age at first conception by applying the following indirect technique because it is not found directly in the BDHS data set.

At first, we have to categories the number of women whether they have at least one child or not. To determine the number, firstly we create two files by using the variable total children ever born from all respondents. Out of 20,127 ever-married women we found 1993 women who have no birth and 18134 women who possess at least one birth. 
Respondents who have no live birth are divided into two groups: (i) pregnant at the time of interview (444) and (ii) first pregnancies terminated at the time of interview (238).

From the 1993 women, 238 were found women whose first pregnancies have terminated. After ignoring the negative conception intervals we got 179 first pregnancies terminated women. We calculate the "Conception Interval" from this file by using the following formula-

Conception interval for non-live birth = Date of first pregnancy terminated- length of gestation- Date of first cohabitation (CMC).

After subtracting 238 from 1993 we have 1755 women from which we determine the responses who are currently pregnant by asking them whether they were currently pregnant or not. We got 444 respondents who were currently pregnant recognized by the respondents. In this file, we estimate the "Conception Interval" by using the following formula-

Conception interval for currently pregnant women $=$ Date of interview - length of gestation-Date of the first cohabitation (CMC).

After ignoring the negative conception intervals we got 388 respondents who were currently pregnant recognized by the respondents.

Again out of 20,127 respondents, there, are 18,134 women who have at least one live birth. To compute conception interval for those who have a first live birth, we use the following formula-

Conception interval for at least one live birth $=$ Date of first live birth $($ CMC $)-9$ (Gestation period $)-$ Date of first marriage (CMC).

After ignoring the negative first conception interval we got 14061 respondents. By adding the 14061 respondents with the 179 respondents who have terminated pregnancy and the 388 respondents who are currently pregnant we finally got 14628 respondents for our current study. Finally, to compute the dependent variable age at the conception of the respondents we use the following formula-

Age at first conception $=$ Age at first cohabitation $+($ conception intervals $/ 12)$

\subsection{Independent Variables}

To find out the age at first conception and its associated factors, we considered different socio-demographic, cultural, and behavioral factors. Because the dependent variable age at first conception is extremely influenced by them. The explanatory variables are respondent's current age (15-24 years, 25-34 years, and 35-49 years), respondent's age at first cohabitation ( $\leq 14$ years, 15-16 years, and $>17$ years), region of residence (urban, rural), division ( Eight administrative regions in Bangladesh), religion (Islam, others), respondent's education (Illiterate, primary education, secondary and above), socio-economic status (poor, middle, rich), nutritional status (Underweight, normal, overweight), husband education (Illiterate, primary education, secondary and above), respondents currently working (Yes, no), partners occupation (Employed, Not employed), spousal age difference ( $<6$ years, 6-10 years, and $>17$ years) and marital duration $(<6$ years, 6-10 years, 10-15 years and > 15 years). The detailed description of the aforesaid independent variables is presented in Table 1.

\subsection{Statistical analysis}

Univariate, bivariate, and multivariate analyses were used to explore the age at first conception among evermarried women in Bangladesh. Descriptive analysis is used to estimate the mean age at first conception by the background characteristics of respondents. Bivariate analysis of chi-square tests was employed to examine the relationships between age at first conception and different background variables. Due to the large P-value in F-statistic (Table 1), the husband's occupation was ignored in the bivariate analysis. Further, multivariate analysis, namely the binary logistic regression is used to determine to what extent these variables are related to variations in the age at first conception in Bangladesh. The presence of multicollinearity is a sensitive issue in the case of multivariate analysis. Therefore we checked multicollinearity before reaching binary logistic regression analysis. In multivariate analysis, the variable 
age at first sexual intercourse was ignored to avoid the problem of multicollinearity with age at first cohabitation. To detect multicollinearity, the threshold value of VIF is 5 or 10 (Gujarati \& Sangeetha, 2008; Montgomery et al., 2012; Chatterjee and Hadi, 2013). The binary dependent variable "age at first conception" was into two categories. One is equal and less than 17.25 years which is the median of the variable and the other is greater than 17.25 years. All the analyses were performed by using SPSS version 25.

\section{Results and Discussion}

\subsection{Mean age at first conception by background characteristics}

The descriptive statistics of age at first conception by different background characteristics are presented in the following table 1. From the mean age of respondents, it is found that the lowest cohort ( $\leq 24$ years) has the lowest mean age at first conception $(16.98 \pm 2.10$ years $)$ and the highest cohort (35-49 years) has the highest mean age at first conception $(18.08 \pm 3.72$ years). The present study shows that the mean age at first conception is 15.51 (SD 2.32) years among the women whose age at first cohabitation is less and equal 14 years followed by 17.27 (SD 2.04) and 20.53(SD 3.03) years for age at first cohabitation 15-16 years and greater than 17 years respectively. From our analysis, we observe that the women living in urban areas have a higher mean age at conception (18.35 years) than those who live in rural areas (17.50 years). There are eight administrative regions in Bangladesh. The behaviors, manners, and cultures are more or less dissimilar in the region and hence age at first conception is unlike. It is seen from Table 1 that the respondents of Sylhet have the highest mean and median age at conception which is 19.03 and 18.42 years followed by Dhaka (18.22 years), Chittagong (17.75 years), Barisal (17.71 years), and the lowest Rangpur (17.31 years) respectively. (18.22 years). The mean age at conception of Khulna and Mymensingh division is the same (17.63 years). We observe that the mean age at conception is higher in other religious women, which are 18.78 is and for Muslim women the mean age at conception is 17.71 years. This study shows that the mean and median age at first conception is higher among the higher educated respondents which are 21.63 years and 20.92 years, whereas overall mean and median ages are 17.82 and 17.25 years respectively. The mean age at conception of the respondents who belong to the high social status is 18.56 years, who possess the middle class is 17.38 years and they have the lower-income class is 17.18 years. Out of the three categories, the respondents who are in the overweight category $(25 \mathrm{~kg} / \mathrm{m} 2$ and above) have the highest mean age at conception, which is 18.26 years. The mean age at first conception for underweight women (below $18.50 \mathrm{~kg} / \mathrm{m} 2)$ and normal $(18.51$ to $24.99 \mathrm{~kg} / \mathrm{m} 2)$ are 17.46 and 17.60 years respectively. Like respondents, education mean age at first conception has been found positively associated with educational levels of husband. The mean age at first conception is found higher (20.02 years) among those whose husbands are highly educated. The working status of the respondents plays a significant role in reproductive characteristics, mainly timing of marriage, conception wait, age at first conception, and first birth. Table 1 shows that the mean age at first conception is relatively higher among the respondents who are not engaged (18.02 years). Probably respondents engaged in work after having their first birth. Partners' occupations show that there is no sufficient variation of age at first conception between employed and non-employed husbands. Our study shows that the mean age at conception is high among the respondents whose spousal age difference is less than six years (i.e., 18.33 years). The mean ages at conception of the respondents whose spousal age difference is 6 to 10 years and 11 years and above are respectively 17.62 and 17.36 years. The findings indicate that the spousal age difference should no longer be in the context of fertility. The study showed that the mean age at first conception was higher (22.42 years) among the respondents whose age at first sex was greater than 18 years and it is lower (15.51 years) whose age at first sex Up to 14 years. The respondents whose marital duration is between 0 to 5 years give the highest age at first conception (18.23 years). From the analysis, we observed that there is no much variation among the different categories of marital duration but the relationship is somewhat inverse.

Overall, the average at first conception of Bangladeshi women is $17.82 \pm 3.29$ years. The median age at first conception is 17.25 years. The results of ANOVA show that all the independent variables consider in this study are significant except partners' occupation.

Table 1: Mean Age at first conception by background characteristics, Bangladesh, 2017

\begin{tabular}{|c|c|c|c|c|c|c|}
\hline Independent variables & Mean & Median & SD & N & F-Value & Sig. \\
\hline \hline
\end{tabular}




\begin{tabular}{|c|c|c|c|c|c|c|}
\hline Respondents current age (Years) & & & & & & \\
\hline$\leq 24$ & 16.98 & 16.92 & 2.10 & 4968 & & \\
\hline $25-34$ & 18.02 & 17.50 & 3.25 & 4526 & 135.22 & .000 \\
\hline$>34$ & 18.08 & 17.33 & 3.72 & 5134 & & \\
\hline \multicolumn{7}{|l|}{ Age at first cohabitation(Years) } \\
\hline$\leq 14$ & 15.51 & 14.92 & 2.32 & 4968 & & \\
\hline $15-16$ & 17.27 & 16.75 & 2.04 & 6171 & 6290.74 & .000 \\
\hline$>17$ & 20.53 & 19.67 & 3.03 & 3489 & & \\
\hline \multicolumn{7}{|l|}{ Type of place of residence } \\
\hline Urban & 18.35 & 17.67 & 3.66 & 5441 & 236.79 & .000 \\
\hline Rural & 17.50 & 17.08 & 3.00 & 9187 & & \\
\hline \multicolumn{7}{|l|}{ Division } \\
\hline Barisal & 17.71 & 17.17 & 3.22 & 1623 & & \\
\hline Chittagong & 17.75 & 17.42 & 2.86 & 1996 & & \\
\hline Dhaka & 18.22 & 17.58 & 3.54 & 2155 & 47.93 & .000 \\
\hline Khulna & 17.63 & 17.00 & 3.26 & 1964 & & \\
\hline Mymensingh & 17.64 & 17.00 & 3.26 & 1611 & & \\
\hline Rajshahi & 17.39 & 16.75 & 3.18 & 1906 & & \\
\hline Rangpur & 17.31 & 16.67 & 3.21 & 1861 & & \\
\hline Sylhet & 19.03 & 18.42 & 3.46 & 1512 & & \\
\hline \multicolumn{7}{|l|}{ Religion } \\
\hline Islam & 17.71 & 17.17 & 3.25 & 13175 & 140.24 & .000 \\
\hline Others & 18.78 & 18.25 & 3.46 & 1453 & & \\
\hline \multicolumn{7}{|l|}{ Respondents education } \\
\hline Illiterate & 17.25 & 16.58 & 3.20 & 2782 & & \\
\hline Primary & 17.06 & 16.67 & 2.84 & 4601 & 922.14 & .000 \\
\hline Secondary & 17.71 & 17.33 & 2.81 & 5767 & & \\
\hline Higher & 21.63 & 20.92 & 3.85 & 1478 & & \\
\hline \multicolumn{7}{|l|}{ Socio-economic status } \\
\hline Poor & 17.18 & 16.75 & 2.83 & 5477 & & \\
\hline Middle & 17.38 & 16.92 & 2.99 & 2820 & 298.16 & .000 \\
\hline Rich & 18.56 & 18.00 & 3.62 & 6331 & & \\
\hline \multicolumn{7}{|l|}{ Nutritional status } \\
\hline Under weight $(\leq 18.5 \mathrm{~kg} / \mathrm{m} 2)$ & 17.46 & 17.00 & 3.02 & 1640 & & \\
\hline Normal $(18.51-24.99 \mathrm{~kg} / \mathrm{m} 2)$ & 17.60 & 17.17 & 3.07 & 7873 & 73.43 & .000 \\
\hline Over weight $(\geq 25 \mathrm{~kg} / \mathrm{m} 2)$ & 18.26 & 17.58 & 3.63 & 5115 & & \\
\hline \multicolumn{7}{|l|}{ Partners education } \\
\hline Illiterate & 17.23 & 16.67 & 3.09 & 3831 & & \\
\hline Primary & 17.14 & 16.75 & 2.80 & 4250 & 533.37 & .000 \\
\hline Secondary & 17.70 & 17.33 & 2.88 & 4022 & & \\
\hline Higher & 20.02 & 19.25 & 3.94 & 2525 & & \\
\hline \multicolumn{7}{|l|}{ Respondents currently working } \\
\hline Yes & 17.55 & 16.92 & 3.26 & 7250 & 96.84 & .000 \\
\hline No & 18.08 & 17.50 & 3.29 & 7378 & & \\
\hline \multicolumn{7}{|l|}{ Partners occupation } \\
\hline Not Employed & 17.95 & 17.50 & 3.28 & 292 & 0.48 & .487 \\
\hline Employed & 17.81 & 17.25 & 3.29 & 14336 & & \\
\hline \multicolumn{7}{|l|}{ Spousal age difference (Years) } \\
\hline$<6$ & 18.33 & 17.67 & 3.50 & 5700 & & \\
\hline$(6-10)$ & 17.62 & 17.17 & 3.07 & 4202 & 125.68 & .000 \\
\hline$>10$ & 17.36 & 16.83 & 3.11 & 4726 & & \\
\hline
\end{tabular}




\begin{tabular}{|c|c|c|c|c|c|c|}
\hline Age at first sex (Years) & & & & & \\
\hline$\leq 14$ & 15.51 & 14.92 & 2.40 & 4523 & & \\
\hline $15-18$ & 17.85 & 17.50 & 2.23 & 7910 & 5902.52 & .000 \\
\hline$>18$ & 22.42 & 21.58 & 3.15 & 2195 & & \\
\hline Marital Duration(Years) & & & & & & \\
\hline$<6$ & 18.23 & 17.67 & 3.06 & 1993 & & \\
\hline$(6-10)$ & 18.22 & 17.75 & 3.24 & 2538 & & \\
\hline $11-15)$ & 18.13 & 17.50 & 3.40 & 2451 & 59.59 & .000 \\
\hline Bangladesh & 17.47 & 16.83 & 3.29 & 7646 & & \\
\hline
\end{tabular}

Note: For all P <0.001; SD = Standard Deviation

\subsection{Bivariate analysis of age at first conception}

This analysis ascertains whether the values of the dependent variable tend to coincide with those of the independent variable. Table 2 represents the bivariate analysis of age at first conception by available background characteristics of the women selected for this research work. In this analysis, the dependent variable "age at first conception" is categorized into two categories. One is less and equals 17.25 years which is the median of the variable and the other is greater than 17.25 years. From Table 2 it has been observed that all the independent variables come out highly significant $(\mathrm{P}<0.001)$ association with the age at first conception. In both cohorts, the current age of the respondents shows positively associated with the age at first conception. Simply, as expected age at first conception has increased with increasing current age respondents. On the other hand age at first, cohabitation shows a negative association with age at first conception. Both variables are statistically significant at $\mathrm{p}<0.001$. The respondents living in rural areas were $66.5 \%$ likely to conceive below or equal age of 17.25 years and $59.0 \%$ of women are likely to conceive greater than 17.25 years. On the other hand, $33.5 \%$ of respondents in urban areas conceive before or equal median age at first conception and $41.0 \%$ at the after median age at first conception. The occurrence of early conception was widespread in Rangpur and Rajshahi region followed by Khulna, Dhaka, Chittagong, Mymensingh, Barisal, and Sylhet region. Table 2 displays that early conception prevailing among Muslim women is higher than the Non-Muslim women. The data shows that respondents' who have higher education only (1.9\%) conceived before 17.25 years. Women who have no formal education $(22.4 \%)$ conceived earlier than that of primary (37.1\%) and secondary (38.7\%), whereas the women who have secondary education $(40.2 \%)$ conceived at age above 17.25 years compared to those who have primary $(25.7 \%)$ and no education $(15.6 \%)$. This variable socioeconomic status has a significant effect on age at conception. $43.2 \%$ of the respondents who are in the lower-income category are found to conceive before or equal age of 17.25 years, $21.3 \%$ of respondents who are in the middle category are found to conceive before or equal age of 17.25 years. On the other hand, $51.2 \%$ of respondents who are in the higher income category are found to conceive after age 17.25 years. From the nutritional status, we observed that normal-weight women take higher age for their first conception. Like respondents' education, partners' education has also found to have a significant effect on respondents' age at first conception. Respondents currently working also have a significant effect on age at first conception. The spouses whose age difference is 6 to 10 years (30\%) are likely to conceive before or equal age of 17.25 years and those whose age difference is 11 years and above, about $36.2 \%$ are likely to conceive before or equal age of 17.25 years. On the other hand, the spouses (49.9\%) whose age difference is 6 to 10 years are likely to conceive after age 16.75 years. As expected, marital duration has also a significant effect on age at first conception. From Table 2 we observed that among the respondents whose marital duration is above15 years $57.8 \%$ conceived earlier than the other groups. Respondents whose marital duration is above 15 years, 46.7 percent are found to have the first conception after 17.25 years. Higher marital duration is associated with lower age at first marriage as well as lower age at first conception.

Table 2: Test of independence between background characteristics and age at first conception in Bangladesh. 


\begin{tabular}{|c|c|c|c|c|}
\hline & $\begin{array}{c}\leq 17.25 \\
\text { (median) years }\end{array}$ & $\begin{array}{c}>17.25 \\
\text { (median) years }\end{array}$ & $\begin{array}{c}\text { statistic } \\
\chi^{2}\end{array}$ & \\
\hline \multicolumn{5}{|l|}{ Respondents current age (Years) } \\
\hline$\leq 24$ & $25.2 \%$ & $18.3 \%$ & & \\
\hline $25-34$ & $33.7 \%$ & $39.1 \%$ & $110.406^{\mathrm{a}}$ & .000 \\
\hline$>34$ & $41.1 \%$ & $42.5 \%$ & & \\
\hline \multicolumn{5}{|l|}{ Age at first cohabitation (Years) } \\
\hline$\leq 14$ & $57.1 \%$ & $10.2 \%$ & & \\
\hline $15-16$ & $38.9 \%$ & $22.8 \%$ & 6815.129 & .000 \\
\hline$>17$ & $4.0 \%$ & $67.0 \%$ & & \\
\hline \multicolumn{5}{|l|}{ Type of place of residence } \\
\hline Urban & $33.5 \%$ & $41.0 \%$ & & .000 \\
\hline Rural & $66.5 \%$ & $59.0 \%$ & $89.166^{\mathrm{a}}$ & \\
\hline \multicolumn{5}{|l|}{ Division } \\
\hline Barisal & $11.4 \%$ & $10.7 \%$ & & \\
\hline Chittagong & $13.0 \%$ & $14.3 \%$ & & \\
\hline Dhaka & $13.3 \%$ & $16.2 \%$ & $286.974^{\mathrm{a}}$ & .000 \\
\hline Khulna & $14.2 \%$ & $12.6 \%$ & & \\
\hline Mymensingh & $11.8 \%$ & $10.3 \%$ & & \\
\hline Rajshahi & $14.7 \%$ & $11.3 \%$ & & \\
\hline Rangpur & $14.6 \%$ & $10.8 \%$ & & \\
\hline Sylhet & $6.9 \%$ & $13.8 \%$ & & \\
\hline \multicolumn{5}{|l|}{ Religion } \\
\hline Islam & $92.9 \%$ & $87.2 \%$ & $131.546^{\mathrm{a}}$ & .000 \\
\hline Others & $7.1 \%$ & $12.8 \%$ & & \\
\hline \multicolumn{5}{|l|}{ Respondents education } \\
\hline Illiterate & $22.4 \%$ & $15.6 \%$ & & \\
\hline Primary & $37.1 \%$ & $25.7 \%$ & $1242.869^{\mathrm{a}}$ & .000 \\
\hline Secondary & $38.7 \%$ & $40.2 \%$ & & \\
\hline Higher & $1.9 \%$ & $18.5 \%$ & & \\
\hline \multicolumn{5}{|l|}{ Socio-economic status } \\
\hline Poor & $43.2 \%$ & $31.5 \%$ & & \\
\hline Middle & $21.3 \%$ & $17.2 \%$ & $373.458^{\mathrm{a}}$ & .000 \\
\hline Rich & $35.5 \%$ & $51.2 \%$ & & \\
\hline \multicolumn{5}{|l|}{ Nutritional status } \\
\hline Under weight $(\leq 18.5 \mathrm{~kg} / \mathrm{m} 2)$ & $12.3 \%$ & $10.1 \%$ & & \\
\hline Normal $(18.51-24.99 \mathrm{~kg} / \mathrm{m} 2)$ & $55.9 \%$ & $51.7 \%$ & $69.998^{\mathrm{a}}$ & .000 \\
\hline Over weight $(\geq 25 \mathrm{~kg} / \mathrm{m} 2)$ & $31.8 \%$ & $38.2 \%$ & & \\
\hline \multicolumn{5}{|l|}{ Partners education } \\
\hline Illiterate & $30.5 \%$ & $21.7 \%$ & & \\
\hline Primary & $33.6 \%$ & $24.4 \%$ & $807.785^{\mathrm{a}}$ & .000 \\
\hline Secondary & $26.9 \%$ & $28.1 \%$ & & \\
\hline Higher & $9.0 \%$ & $25.7 \%$ & & \\
\hline \multicolumn{5}{|l|}{ Respondents currently working } \\
\hline Yes & $53.6 \%$ & $45.4 \%$ & $99.381^{\mathrm{a}}$ & .000 \\
\hline No & $46.4 \%$ & $54.6 \%$ & & \\
\hline \multicolumn{5}{|l|}{ Spousal age difference(in years) } \\
\hline$<6$ & $33.8 \%$ & $44.2 \%$ & & \\
\hline$(6-10)$ & $30.0 \%$ & $27.5 \%$ & $179.959^{\mathrm{a}}$ & .000 \\
\hline$>10$ & $36.2 \%$ & $28.3 \%$ & & \\
\hline \multicolumn{5}{|l|}{ Marital Duration } \\
\hline$<6$ & $11.8 \%$ & $15.5 \%$ & & \\
\hline
\end{tabular}




\begin{tabular}{|c|c|c|c|c|}
\hline$(6-10)$ & $15.2 \%$ & $19.5 \%$ & $183.442^{\mathrm{a}}$ & \\
\hline$(11-15)$ & $15.3 \%$ & $18.3 \%$ & & .000 \\
\hline $15>$ & $57.8 \%$ & $46.7 \%$ & & \\
\hline
\end{tabular}

Note: For all $\mathbf{P}<\mathbf{0 . 0 0 1}$

\subsection{Determinants of age at first conception: Logistic Regression}

In addition to studying the test of independence of age at first conception with background characteristics of the respondents', logistic regression is also employed to identify the risk or prognostic factors. The dichotomized dependent variable age at first conception was used in this model, by considering the value of 0 for median age at first conception $\leq 17.25$ years and the value of 1 for age being greater than 17.25 years. Table 3 gives the estimation of the logistic regression coefficients $(\beta)$ corresponding to the independent variables, significance probability, 95\% CI, and relative odds for each category of the categorical explanatory variables. Among the variables considered in the logistic regression analysis, the variables respondents' current age, age at first cohabitation, respondents' education, and partners' education are highly significant with age at first conception. The variables region of residence and spousal age difference are partially significant with age at first conception in Bangladesh.

Table 3 showed that respondents' current age was significantly negatively associated with age at first conception. Respondents aged 25-34 and those aged 35-49 were 62.9 percent and 32.8 percent less likely to have the first conception at age above 17.25 years, compared to those whose current age is $\leq 24$ years. Table 3 also reveals that age at first marriage exposed significantly negatively correlated with age at first conception. Respondents whose age at first cohabitation was 15-16 and 17 years and above were 98.9 percent and 96.3 percent less likely to have the first conception at age above 17.25 years, compared to those whose age at first cohabitation is $\leq 14$ years. The respondent of Dhaka, Chittagong, Rajshahi, and Sylhet region was less likely and those of Khulna, Mymensingh and Rangpur region were more likely to have the first conception at age above 17.25 years, compared to the Barisal region. Respondents' education exposed a significantly negatively associated with age at first conception. Respondents with primary, secondary, and higher education, were respectively $55.7 \%, 63.7 \%$, and $62.1 \%$ less likely to have the first conception at age above 17.25 years compared to those with illiterate women. Like Respondents' education the variable partners' education also significantly negatively correlated with age at first conception. Respondents with primary $(\mathrm{OR}=0.782,95 \% \mathrm{CI}=0.648-0.945, \mathrm{P}<0.001)$, secondary $(\mathrm{OR}=0.743,95 \% \mathrm{CI}=0.622-0.886, \mathrm{P}$ $<0.01)$ and higher educated husband $(\mathrm{OR}=0.838,95 \% \mathrm{CI}=0.710-0.989, \mathrm{P}<0.05)$ were respectively less likely to having first conception at age above 17.25 years, compared to those with illiterate women. The spousal age difference was found to have significantly positively associated with age at first conception. Spousal age difference within 6 to 10 years $(\mathrm{OR}=1.478,95 \% \mathrm{CI}=1.322-1.653, \mathrm{P}<0.001)$ were significantly more likely to have the first conception at age above 17.25 years, compared to those whose age gap is less than 6 years. No other variables were found to have a significant effect on the age of first conception in binary logistic regression analysis.

Table 3: Logistic regression estimation for the simultaneous effects of all factors in the model of age at first conception

\begin{tabular}{|c|c|c|c|c|c|c|}
\hline \multirow[t]{2}{*}{ Factors } & \multirow[t]{2}{*}{ Co-efficient( $\beta$ ) } & \multirow[t]{2}{*}{ S.E. } & \multirow[t]{2}{*}{ P-value } & \multirow[t]{2}{*}{$\begin{array}{c}\text { Odds } \\
\text { ratio[exp } \beta]\end{array}$} & \multicolumn{2}{|c|}{$\begin{array}{c}\text { 95\% C.I.for } \\
\text { EXP(B) }\end{array}$} \\
\hline & & & & & Lower & Upper \\
\hline \multicolumn{7}{|c|}{ Respondents current age (Years) } \\
\hline$\leq 24$ & & & .000 & 1.000 & & \\
\hline $25-34$ & -.993 & .139 & .000 & $.371 * * *$ & .282 & .487 \\
\hline$>34$ & -.397 & .074 & .000 & $.672 * * *$ & .581 & .778 \\
\hline \multicolumn{7}{|c|}{ Age at first cohabitation (Years) } \\
\hline$\leq 14$ & & & .000 & 1.000 & & \\
\hline $15-16$ & -4.539 & .084 & .000 & $.011 * * *$ & .009 & .013 \\
\hline$>17$ & -3.310 & .074 & .000 & $.037 * * *$ & .032 & .042 \\
\hline \multicolumn{7}{|c|}{ Type of place of residence } \\
\hline Urban & & & & 1.000 & & \\
\hline
\end{tabular}




\begin{tabular}{|c|c|c|c|c|c|c|}
\hline Rural & -.085 & .054 & .120 & .919 & .826 & 1.022 \\
\hline \multicolumn{7}{|l|}{ Division } \\
\hline Barisal & & & .000 & 1.000 & & \\
\hline Chittagong & -.020 & .106 & .852 & .980 & .796 & 1.208 \\
\hline Dhaka & -.331 & .103 & .001 & $.718 * * *$ & .587 & .878 \\
\hline Khulna & .047 & .101 & .642 & 1.048 & .859 & 1.279 \\
\hline Mymensingh & .081 & .102 & .424 & 1.085 & .889 & 1.325 \\
\hline Rajshahi & -.016 & .106 & .880 & .984 & .800 & 1.211 \\
\hline Rangpur & .000 & .103 & .999 & 1.001 & .818 & 1.222 \\
\hline Sylhet & -.141 & .105 & .181 & .869 & .707 & 1.068 \\
\hline \multicolumn{7}{|l|}{ Religion } \\
\hline Islam & & & & 1.000 & & \\
\hline Others & -.089 & .084 & .287 & .915 & .776 & 1.078 \\
\hline \multicolumn{7}{|l|}{ Respondents education } \\
\hline Illiterate & & & .000 & 1.000 & & \\
\hline Primary & -.813 & .145 & .000 & $.443 * * *$ & .334 & .590 \\
\hline Secondary & -1.014 & .135 & .000 & $.363 * * *$ & .278 & .473 \\
\hline Higher & -.971 & .125 & .000 & $.379 * * *$ & .297 & .484 \\
\hline \multicolumn{7}{|l|}{ Socio-economic status } \\
\hline Poor & & & .578 & 1.000 & & \\
\hline Middle & -.058 & .067 & .385 & .944 & .828 & 1.075 \\
\hline Rich & -.065 & .068 & .341 & .937 & .820 & 1.071 \\
\hline \multicolumn{7}{|l|}{ Nutritional status } \\
\hline Under weight $(\leq 18.5 \mathrm{~kg} / \mathrm{m} 2)$ & & & .686 & 1.000 & & \\
\hline Normal $(18.51-24.99 \mathrm{~kg} / \mathrm{m} 2)$ & .045 & .082 & .583 & 1.046 & .891 & 1.229 \\
\hline Over weight $(\geq 25 \mathrm{~kg} / \mathrm{m} 2)$ & -.018 & .053 & .727 & .982 & .885 & 1.089 \\
\hline \multicolumn{7}{|l|}{ Partners education } \\
\hline Illiterate & & & .011 & & & \\
\hline Primary & -.245 & .096 & .011 & $.782 * *$ & .648 & .945 \\
\hline Secondary & -.298 & .090 & .001 & $.743 * * *$ & .622 & .886 \\
\hline Higher & -.177 & .085 & .036 & $.838 *$ & .710 & .989 \\
\hline \multicolumn{7}{|l|}{ Respondents currently working } \\
\hline Yes & & & & 1.000 & & \\
\hline No & -.082 & .050 & .100 & .921 & .835 & 1.016 \\
\hline \multicolumn{7}{|l|}{ Spousal age difference(in years) } \\
\hline$<6$ & & & .000 & 1.000 & & \\
\hline$(6-10)$ & .391 & .057 & .000 & $1.478 * * *$ & 1.322 & 1.653 \\
\hline$\geq 11$ & .042 & .061 & .486 & 1.043 & .926 & 1.175 \\
\hline \multicolumn{7}{|l|}{ Marital Duration } \\
\hline$<6$ & & & .000 & 1.000 & & \\
\hline$(6-10)$ & -.215 & .157 & .171 & .807 & .593 & 1.098 \\
\hline$(11-15)$ & .194 & .119 & .103 & 1.214 & .961 & 1.534 \\
\hline 15> & .101 & .086 & .240 & 1.107 & .934 & 1.311 \\
\hline Constant & 4.291 & .174 & .000 & 73.011 & & \\
\hline
\end{tabular}

Note: $* * * \mathbf{P}<\mathbf{0 . 0 0 1}, * * \mathbf{P}<\mathbf{0 . 0 1}, * \mathbf{P}<\mathbf{0 . 0 5} ;$ S.E. $=$ Standard Error

\section{Discussion}

This study investigates the age at first conception and its determinants of ever-married women in Bangladesh. The major findings of different segments of age at first conception and their probable interpretation are discussed in this section.

The mean age at first conception for the Bangladeshi women is $17.82 \pm 3.29$ years which is almost identical to other studies conducted in Bangladesh where the mean $( \pm \mathrm{SD})$ age of the adolescent pregnancy was 17.7 
$( \pm 2.79)$ years (Sarder et al. 2020). A similar pattern was observed with another study conducted in Bangladesh, where most of the conception occurred between the ages of 15-19 years (Sayem \& Nury, 2011). The result of this study shows that the average age at first conception in Bangladesh is unexpectedly lower even in legal age at marriage was fixed at 18.00 years. Thus, the minimum legal age at first marriage in Bangladesh should be strictly enforced to avoid premature pregnancy as well as to reduce high fertility. The respondents who have illiterate and primary educated have the lowest mean and median age at first conception respectively. Highly educated women are conscious about marital age and health and so it assistances in women empowerment (Duflo, 2012; Porter, 2013; Mim, 2017). The lower mean age at first marriage of illiterate and primary educated women may be the reason for the lower mean age at first conception in Bangladesh. Therefore, to reduce fertility in Bangladesh the mean age at first marriage of low educated women should be increased because it directly affects the age at first conception in Bangladesh. The study found that women living in rural areas have the lowest mean and median of 17.50 and 17.08 years respectively. Similar findings have been found in the study of Sayem and Nury (2011). Like the type of place of residence, there is a substantial variation in age at first pregnancy was observed among the region of residence in Bangladesh. These results are also reliable with the results of preceding studies (Islam et al. 2017). Muslim respondents have the lowest mean and median age at first conception of 17.71 and 17.17 years respectively. Therefore, appropriate steps should be taken to increase the average age at first conception among Muslim women in Bangladesh. Like respondents' education, partners' education also found the lowest mean and median age at first conception for illiterate and primary educated women. Child marriage of illiterate and primary educated women impacts the age at first conception in Bangladesh. The mean and median age at conception is higher among the high social status of the women. Higher age at first marriage of the women belongs to higher social status may be the important reason for higher mean age at first conception. Nutritional status is one of the most important determinates of age in the first conception. The respondents who are underweight $(18.5 \mathrm{~kg} / \mathrm{m} 2)$ have the lowest mean and median age at first conception of 17.46 and 17 years respectively. Well-nourished women take relatively more time for the first conception. On the other hand, being Overweight women could increase the risk of disease in later life such as cardiovascular, diabetes mellitus, pre-eclampsia, gestational diabetes, and hypertension (Athukorala et al. 2010; Bishr et al. 2020). The spouses whose age difference is 11 years and above have the lowest mean and median age at first conception of 17.36 and 16.83 years respectively. The study also supported the finding that the mean and median age of conception in Bangladeshi couples tend to decline with the increasing spousal age difference (Sarder et al. 2020). Marital duration is often a significant predictor of individual emotional and physical well-being across the life span (Horwitz, White, \& Howell- White, 1996; Wickrama, Lorenz, Conger, \& Elder, Jr., 1997). Duration of marital life is also an important factor that influences age at conception. The respondents whose marital duration is 15 years and above have the lowest mean and median age at first conception of 17.42 and 16.83 years respectively.

From the bivariate analysis, we have observed that all the considered independent variables have a significant effect on age at first conception. To investigate the prognostic factors of age at first marriage we have employed multivariate logistic regression, considering the variables found significant in bivariate analysis. In logistic regression analysis, we have found current age, age at first cohabitation, respondents' education, and partners' education are highly significant effects on age at first conception. The findings of the logistic regression analysis revealed that women aged 25-34 were less likely to have the first conception at age above 17.25 years, compared to the women aged $\leq 24$ years. Studies found that the main intention of marriage in developing countries is to bear children and in most cases, early marriage is related to early childbearing (Ikamari, 2005). Results revealed that women who married later ( $>17$ years) were 0.037 times $(\mathrm{OR}=0.037,95 \% \mathrm{CI}: 0.032-0.042, \mathrm{p}<0.001)$ less likely to have the first conception at age above 17.25 years compared with women who married earlier ( $\leq 14$ years). Though, this study is not stable to earlier studies conducted in Bangladesh (Ali et al. 2017). Results of the study show that respondents of Dhaka, Chittagong, Rajshahi, and Sylhet region were less likely to have the first conception at age above 17.25 years compared to the Barisal region. Higher age at marriage of these divisions might be the cause of higher age at first birth among the respondents living in Dhaka, Chittagong, Rajshahi, and Sylhet region. On the other hand, proper steps should be taken to increase the age at first conception in Khulna, Rangpur, and Mymensingh divisions to reduce fertility. The findings show that secondary and higher educated women were less likely to have the first conception at age above 17.25 years compared to those with illiterate 
women. Similar results were observed in various previous studies (Chedraui et al. 2004; Nahar \& Min, 2008; Rosenberg et al. 2015; Mpilambo et al. 2017). Like women's education, husband education also has a strong significant impact on age at first conception in Bangladesh and it can help to delay adolescent birth (Nahar \& Min, 2008). Finally, the variable spousal age difference between 6 to 10 years was significantly more likely to have the first conception at age above 17.25 years, compared to the age gap is less than 6 years. Lower spousal age difference indicates higher age at first marriage and higher age at first conception. Age gaps between brides and grooms could increase the age at first conception; thus, there should minimum spousal age difference between couples in Bangladesh.

Overall, from the above finding, it may be concluded that to increase the age at first marriage fruitful policies should be adopted to increase the educational level for both partners. In this context, secondary education can be implemented inevitably. Awareness can be created regarding the negative consequence of health due to early marriage and early conception among teenage females in Bangladesh.

\section{Conclusion and Recommendation}

This research work is an attempt to study the age at first conception and its determinants of ever-married women in Bangladesh. In this study, we have employed different techniques to determine the age at first conception in Bangladesh. To understand the significance of different background characteristics on age at first conception we have employed the bivariate and multivariate analysis. The logistic regression method is used to investigate the prognostic factors of age at first conception. The results indicate that marked variations may arise due to the differentials of age at first conception and different socio-demographic, cultural, and behavioral factors. Studies found that the average age at first conception of Bangladeshi women is $17.82 \pm 3.29$ years. Findings suggest that respondents' current age, age at first cohabitation, respondents' education, partners' education, region of residence, and spousal age difference are important determinants of age at first conception in Bangladesh.

The findings obtained from this study may have some policy implications that might be helpful for the population scientists and policy-makers to take appropriate steps to increase the age at first marriage, increasing the level of fecundability, and finally to increase the age at first conception for reducing the fertility in Bangladesh. The variables that are found to have a significant effect on the vital events mentioned above may have important policy implications.

This task is complicated because we have estimated some vital events based on birth history inquiry (retrospective survey) using different techniques. Due to the memory lapse of the respondents, there is sufficient scope of errors in the responses. Therefore, the findings are not free to form errors. Thus, for conducting further in-depth analysis regarding reproductive behavior for women in Bangladesh, longitudinal data must be needed, which could be possible in the implementation of a vital registration system in a country like Bangladesh.

\section{References}

1. Alam, M. M., Hoq, M. N., \& Hossain, M. E. (2016). Determinants of age at first motherhood in Bangladesh. IIUC Business Review, 5: 25-40

2. Ali, M., Alauddin, S., Khatun, M. F., Maniruzzaman, M., \& Islam, S. M. S. (2020). Determinants of early age of mother at first birth in Bangladesh: a statistical analysis using a two-level multiple logistic regression model. Journal of Public Health, 1-7. doi: 10.1007/s10389-020-01228-9.

3. Athukorala, C., Rumbold, A. R., Willson, K. J., \& Crowther, C. A. (2010). The risk of adverse pregnancy outcomes in women who are overweight or obese. BMC pregnancy and childbirth, 10(1), $1-8$.

4. Bishr, N. T., M. S. Darweesh, E. G. Amer, A. M. Abul-Fadl, and A. Al-Jawaldeh (2020). Overweight Increases the Risk of Right Ventricular Dysfunction in the Non-Breastfed Infants". International Journal of Scientific Research and Management, 8(10):411-20, doi:10.18535/ijsrm/v8i10.mp02.

5. Chatterjee, S., Hadi, A.S. (2013). Regression Analysis by Example, John Wiley 
6. Chedraui, P. A., Hidalgo, L. A., Chávez, M. J., \& Miguel, G. S. (2004). Determinant factors in Ecuador related to pregnancy among adolescents aged 15 or less. Journal of Perinatal Medicine 32: 337-341.

7. Chen X. K., Wen S.W., Fleming N., Demissie K., Rhoads G.G., et al. (2007). Teenage pregnancy and adverse birth outcomes: A large population based retrospective cohort study. Intern J Epidemiol 36: 368-373.

8. Darroch, J. E., Woog, V., Bankole, A., \& Ashford, L. S. (2016). Adding it up: costs and benefits of meeting the contraceptive needs of adolescents.New York: Guttmacher Institute

9. Duflo, E. (2012). Women empowerment and economic development. Journal of Economic literature, 50(4), 1051-79.

10. Gujarati, D. N and Sangeetha (2008). Basic Econometrics, $4^{\text {th }}$ ed., the Tata McGraw-Hill Companies, India

11. Horwitz, A. V., White, H. R., \& Howell-White, S. (1996). Becoming married and mental health: A longitudinal study of a cohort of young adults. Journal of Marriage and the Family, 58(4), 895907. https://doi.org/10.2307/353978

12. Ikamari, L. D. (2005). The effect of education on the timing of marriage in Kenya. Demographic research, 12, 1-28.

13. Islam, M. M., Islam, M. K., Hasan, M. S., \& Hossain, M. B. (2017). Adolescent motherhood in Bangladesh: Trends and determinants. PloS one, 12(11), e0188294.

14. Jolly M., Sebire N., Harris J., Robinson S., Regan, L. (2000). The risks associated with pregnancy in women aged 35 years or older. Hum Reprod 15: 2433-2437.

15. Jones, G. W. (2007). Fertility Decline in Asia: The Role of Marriage Change. Asia-Pacific Population Journal, 22(2).

16. Joseph, K. S., Allen, A. C., Dodds, L., Turner, L. A., Scott, H., \& Liston, R. (2005). The perinatal effects of delayed childbearing. Obstetrics \& Gynecology, 105(6), 1410-1418.

17. Liu X., Zhang W. (2014). Effect of maternal age on pregnancy: A retrospective cohort study. Chin Med J 127: 2241-2246.

18. Luke, B., \& Brown, M. B. (2007). Elevated risks of pregnancy complications and adverse outcomes with increasing maternal age. Human reproduction, 22(5), 1264-1272.

19. Mehra S., \& Agrawal D. (2004). Adolescent health determinants for pregnancy and child health outcomes among the urban poor. Indian Pediatrics 2004, 41:137-45.

20. Mim, S. A. (2017). Effects of child marriage on girls' education and empowerment. J. Educ. Learn, 11(1), 9.

21. Montgomery, D.C., Peck, E.A., Geoffrey Vining, G. (2012). Introduction to Linear

22. Mpilambo, J. E., Appunni, S. S., Kanayo, O., \& Stiegler, N. (2017). Determinants of early marriage among young women in Democratic Republic of Congo. Journal of Social Sciences, 52(1-3), 82-91. DOI: 10.1080/09718923.2017.1322393.

23. Nahar Q. and Min, H. (2008). Trends and Determinants of Adolescent Childbearing in Bangladesh, DHS Working Paper No. 48, Demographic and Health Research, Calverton, MD.

24. National Institute of Population Research and Training (NIPORT), and ICF. (2019). Bangladesh Demographic and Health Survey 2017-18: Key Indicators. Dhaka, Bangladesh, and Rockville, Maryland, USA: NIPORT, and ICF.

25. National Institute of Population Research and Training (NIPORT), Mitra and Associates, and ICF International. (2016). Bangladesh Demographic and Health Survey 2014. Dhaka, Bangladesh, and Rockville, Maryland, USA: NIPORT, Mitraand Associates, and ICF International.

26. Papri F.S, Khanam Z., Ara S., Panna M.B. (2016). Adolescent pregnancy: risk factors, outcome and prevention Chattagram Maa-O-Shishu. Hospital Med College J 15:53-56

27. Porter, E. (2013). Rethinking women's empowerment. J. Peacebuilding Dev. 8 (1), 1-14.

28. Rosenberg, M., Pettifor, A., Miller, W. C., Thirumurthy, H.,Emch, M., Afolabi, S. A.,... Tollman, S. (2015). Relationship between school dropout and teen pregnancy among rural South African young women. International Journal of Epidemiology, 44: 928-936. doi: 10.1093/ije/dyv007. 
29. Saleheen, A. A. S., Afrin, S., Kabir, S., Habib, M. J., Zinnia, M. A., Hossain, M. I., ... \& Talukder, A. (2021). Sociodemographic factors and early marriage among women in Bangladesh, Ghana and Iraq: An illustration from Multiple Indicator Cluster Survey. Heliyon, 7(5), e07111.

30. Sarder, M. A., Alauddin, S., \& Ahammed, B. (2020). Determinants of teenage marital pregnancy among bangladeshi women: An analysis by the cox proportional hazard model. Social Health and Behavior, 3(4), 137.

31. Sayem, A. M., \&Nury, A. T. M. (2011). Factors associated with teenage marital pregnancy among Bangladeshi women. Reproductive Health, 8, 16. http://doi.org/10.1186/1742-4755-8-16.

32. UNFPA. Girlhood, not motherhood: Preventing adolescent pregnancy. New York: UNFPA; 2015.

33. Wickrama, K. A. S., Lorenz, F. O., Conger, R. D., \& Elder, G. H., Jr. (1997). Marital quality and physical illness: A latent growth curve analysis. Journal of Marriage and the Family, 59(1), 143155. https://doi.org/10.2307/353668 